\title{
FRONTERAS, REPRESENTACIONES Y RELATOS ESPACIALES: LA IGLESIA CATÓLICA SALTEÑA EN EL CASO DEL CULTO DE URKUPIÑA EN LA CIUDAD DE SALTA - ARGENTINA
}

1 Doctora en Comunicación por la Universidad Nacional de La Plata. Becaria Posdoctoral del CONICET. Lugar de trabajo: Instituto de Bio y Geociencias del NOA. Auxiliar docente en las cátedras de Semiótica General, Semiótica de la Cultura y Análisis del Discurso en la Universidad Nacional de Salta.

Email para contacto: danielanavalefavi @gmail.com

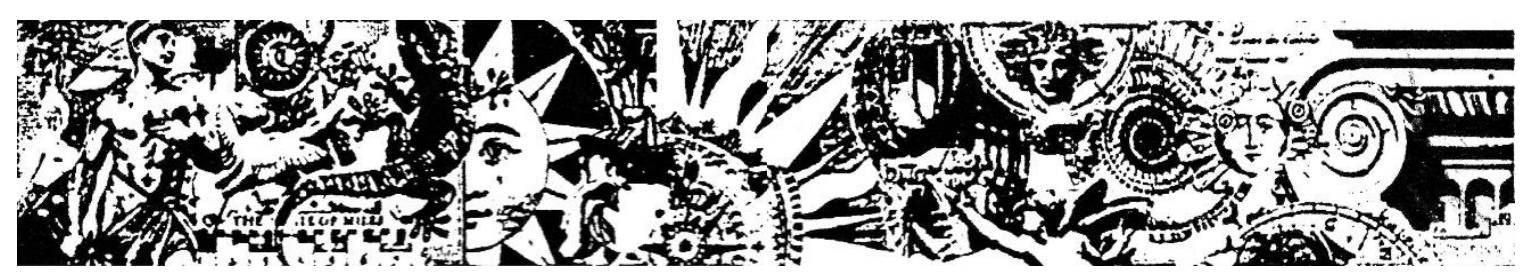

Resumen: El trabajo retama una mirada interdisciplinaria en el cruce de aportes que provienen de la semiótica, la comunicación/ cultura y estudios sobre la religiosidad de vertientes antropológicas, históricas y saciológicas para comprender cómo la Iglesia Católica salteña ejerce el poder de controlar, disciplinar y legislar los espacios del culto de Urkupiña en la ciudad de Salta por ser -además- una devación alejada de los rituales del canon católico y más cercana al carnaval bajtiniano. Para ello, se intenta explorar una serie de acontecimientas vinculadas a la llegada de la Virgen a la ciudad de Salta en el año 2014. Allí, se mira cómo el recorrida que hace el bulto articula un relato espacial desde la visión eclesial la que habla, de algún moda, sobre cómo la hegemonía piensa que se puede habitar y transitar la ciudad. El trabajo explora la significación de los recorridos, las legislaciones espaciales, las fronteras en un acto de fijación y delimitación de un campo cerrada discursivo dande, de alguna manera, la Iglesia activa los campos de representación de esos espacios e impregna a la devación con los mismos.

Palabras-Clave: rizoma- representaciones- relatos espaciales- fronteras. 


\section{BDRDERS, REPRESENTATIONS AND SPATIAL STORIES: THE SALTEÑA CATHDLIC CHURCH IN THE CASE OF THE URKLPIÑA CULT IN THE CITY OF SALTA- ARGENTINA}

ABSTRACT: THE WDRK TAKES AN INTERDISCIPLINARY LODK AT THE INTERSECTION OF CDNTRIBUTIONS THAT CDME FRDM SEMIDTICS, CULTURAL COMMUNICATION AND STUDIES ON THE RELIGIOSITY OF ANTHROPOLOGICAL, HISTORICAL AND SOCIOLOGICAL ASPECTS TO UNDERSTAND HOW THE CATHOLIC CHURCH DF SALTA EXERCISES THE POWER TO CONTROL. DISCIPLINE AND LEGISLATE SPACES OF THE CULT DF URKLPINA IN THE CITY DF SALTA FDR BEING - IN ADDITION - A DEVDTIIN FAR FRDM THE RITUALS OF THE CATHOLIC CANDN AND CLOSER TO THE BAJTINIAN CARNIVAL.

TO DO THIS, AN ATTEMPT IS MADE TO EXPLORE A SERIES OF EVENTS LINKED TO THE ARRIVAL OF THE VIRGIN IN THE CITY DF SALTA IN 20I4. THERE, WE LODK AT HOW MAKES ARTICLLLATES A SPATIAL ACCDUNT FRDM THE ECCLESIAL VISION DF WHAT IT SPEAKS, SDMEHIW, םN HDW THE HEGEMUNY THINKS THAT THE CITY CAN BE INHABITED AND TRANSIT. THE WDRK EXPLDRES THE SIGNIFICANCE OF THE RDUTES, THE SPATIAL LEGISLATION, THE BDRDERS IN AN ACT OF FIXING AND DELIMITING A CLOSED DISCURSIVE FIELD WHERE, IN SDME WAY, THE CHURCH ACTIVATES THE FIELDS OF REPRESENTATION OF THOSE SPACES AND IMPREGNATES DEVDTION WITH THE THEMSELVES.

KEYWDRDS: RHIZDME- REPRESENTATIONS- SPATIAL STORIES- BORDERS.

FRONTEIRAS, REPRESENTAÇD̃ES E HISTÓRIAS ESPACIAIS: A IGREJA CATÓLICA SALTEÑA NU CASQ DU CULTO URKUPINIA NA CIDADE DE SALTA - ARGENTINA

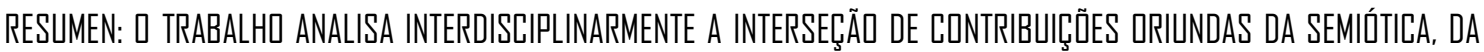

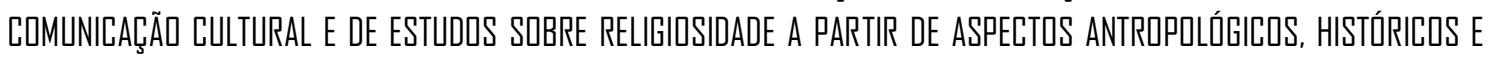

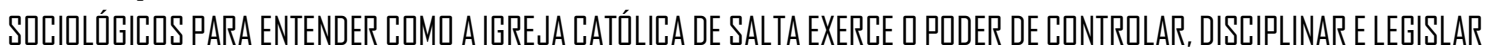
ESPAÇDS DO CULTO DE URKUPIÑA NA CIDADE DE SALTA POR SER - ALÉM DISSO - UMA DEVQÇ̃̃̃ LUNGE DOS RITUAIS DO CÂNGNE CATÓLICD E MAIS PERTO DO CARNAVAL BAJTINIAND.

PARA ISSD, É FEITA UMA TENTATIVA DE EXPLDRAR UMA SÉRIE DE EVENTUS LIGADOS À CHEGADA DA VIRGEM À CIDADE DE SALTA

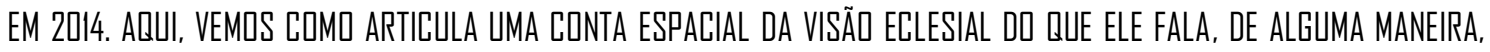

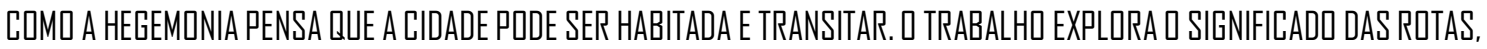

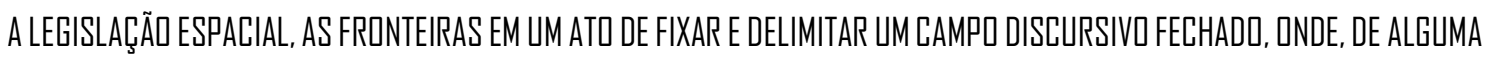

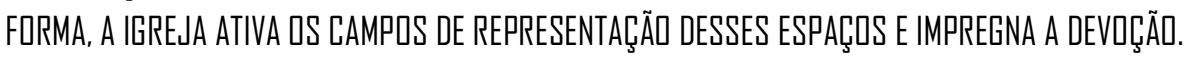

PALABRAS CLAVE: RIZUMA- REPRESENTAÇ̃̃ES - HISTÓRIAS ESPACIAIS- FRDNTEIRAS. 
El caso

Desde La Virgen de Urkupiña es un culto migrante y mariano que tiene sus orígenes en la etapa colonial de Bolivia ${ }^{2}$. A lo largo de los años, se fue expandiendo de su lugar de procedencia (Cochabamba) para llegar a distintos países latinoamericanos y europeos.

En la ciudad de Salta, Argentina ${ }^{3}$, la advocación tiene la configuración de un rizoma (DELEUZE y GUATTARI, 1972), es decir, se encuentra en permanente territorialización en el espacio público de la ciudad, haciéndose legible, por ejemplo, en los múltiples negocios destinados a la comercialización de los elementos utilizados durante los rituales.

La particularidad de la devoción es que si bien es un culto migrante, ha sido asimilado por familias citadinas que celebran las novenas en sus casas, llevan sus imágenes en procesiones por diversas calles de la ciudad y le realizan grandes fiestas en sus hogares o salones alquilados con juegos, comidas y bebidas. La manera de festejar el culto implica ciertas correlaciones con las manifestaciones de la cultura popular/carnavalesca bajtiniana que se manifiestan en las fiestas en honor al culto: allí, los devotos no son simples espectadores, hay un contacto libre y familiar entre los presentes. Pero, especialmente, se presenta el principio corporal y material de la fiesta dado que los banquetes que se comparten son abundantes y productos de lazos comunitarios (todos colaboran para compartir la comida) y se "vive" con alegría el momento del festejo que se manifiesta, por ejemplo, en los cantos de los devotos (que no responden a la música católica) y los brindis con cerveza (bebida que también se utilizará para la challa, es decir, una forma de bendición de objetos rituales).

En ese sentido, cabe destacar que la Virgen de Urkupiña tiene algunas configuraciones similares al arco de las formas de religiosidad andina ${ }^{4}$ que se pueden

\footnotetext{
2 Oficialmente Estado Plurinacional de Bolivia, es un país soberano situado en la región centrooccidental de América del Sur. Está organizado en nueve departamentos. Su capital constitucional es Sucre, sede del órgano judicial; la ciudad de La Paz es la sede de los órganos ejecutivo, legislativo y electoral.

${ }^{3}$ Salta es una ciudad capital de la provincia de Salta, República Argentina. Tiene una población de 783.323 habitantes, siendo la ciudad más poblada de la provincia y la séptima del país. Su área metropolitana, denominada Gran Salta, está compuesta por once municipios y tiene a una población de 618375 habitantes. (Información extraída de: https://www.indec.gob.ar/. Última consulta: 25 de marzo de 2020).

${ }^{4}$ Kaliman sostiene que "lo andino" como "inconsciente colectivo" es más una dimensión política que intenta generar una imagen totalizante y está vinculada a una especie de restauración panandina. Otros autores, desde una perspectiva geográfica y que recuperan aportes de la arqueología piensan que existen países Andinos, los cuales serían "Venezuela, Colombia, Ecuador, Bolivia, Perú, Chile y ESPAÇO E CULTURA, UERJ, RJ, JUN./JUL DE 2020, N. 47, P. 122-139. http://www.e-publicacoes.uerj.br/index.php/espacoecultura/
} 
leer, por ejemplo, en la denominación por parte de sus creyentes como "Mamita", apelativo que responde a usos que también se efectúan en cultos como el caso de la Virgen Nuestra Señora de la Candelaria que se festeja en Puno, Perú, y en Humahuaca, Argentina (PODJAJCER y MENNELLI, 2009). En ambos lugares, se presenta un proceso donde resulta intercambiable el término de Pachamama-madre con virgencitamamita, dando cuenta de un "complejo mapa de creencias católico populares vinculadas estrechamente a rituales y performances representados e identificados por sus actores como acciones sociales de su vida cotidiana” (PODJAJCER y MENNELLI, 2009, p. 90). Esta cartografía de creencias se presenta en Urkupiña también a través de una continuidad de elementos rituales que se utilizan tanto en la Pachamama como en la devoción, entre los cuales se puede mencionar: las hojas de coca, la cerveza para la challa $^{5}$, los sahumerios e inciensos que son propios de la cultura andina.

Uno de los pilares fundamentales de los pueblos andinos ${ }^{6}$ era el sentido colectivo que tenía su principal unidad en el concepto de familia (GUARDIA CRESPO, 2018), representación que se repite en la organización de los rituales de la Virgen. Así, los devotos asumen responsabilidades como la preparación de la comida, la búsqueda de equipos de música para las fiestas e inmediatamente se convierten en "madrinas" y

Argentina. Entre estos países se pueden diferenciar los plenamente andinos como Bolivia, Colombia, Ecuador y Perú, de aquellos que poseen un ámbito andino más marginal, tal el caso de Venezuela, Chile y Argentina" (GUERRERO et. al., 2011). El culto de Urkupiña, como culto boliviano tiene elementos andinos que se entraman en una territorialidad que involucra al Noroeste Argentino. Esto posibilitaría comprender una dimensión más de las apropiaciones que se hacen del culto.

${ }^{5}$ La challa es una práctica que también se realiza durante la fiesta de la Pachamama (madre tierra) y consiste en lanzar cervezas, hojas de coca, papel picado y -en el ritual andino mencionado- comida. En Urkupiña, funciona como una manera de bendición más popular: así, se challan imágenes, los autos de los promesantes (para asegurar que la Virgen los proteja), las alasitas o sobre cualquier otro bien material que desee el creyente. Este tipo de práctica ritual se puede efectuar tanto por hombres como por mujeres, a diferencia de las bendiciones católicas que únicamente pueden ser realizadas por sacerdotes. Aquí, se observa este rasgo popular pero, también, el espesor temporal ligado a una práctica andina que tiene sus continuidades en otros rituales marianos de la región andina. Por otra parte, las alasitas son objetos en miniatura que representan autos, casas y todo lo que el promesante necesite. Se utilizan en otras festividades como la del Ekeko (CIRCOSTA, 2010).B

${ }^{6}$ Existe una indagación que piensa la relación entre la Imagen de la Virgen María, el cerro Potosí y el apu Pachamac, donde en una pintura de "la Virgen- Cerro" en el museo de La Moneda en Potosí se da cuenta de éste proceso: "En tiempos virreinales fue representada la Virgen María como "madre tierra" en forma explícita; el ejemplo más importante es el cuadro existente en el museo de la Moneda (Potosí) donde María y el Cerro de Potosí son un todo. En el lienzo se muestra la montaña con rostro femenino y un par de manos con las palmas abiertas. Es la imagen de María inserta en el cerro y coronada por la Trinidad. Al pie pueden verse el papa Pablo III, un Cardenal y un Obispo; al lado opuesto, Carlos V y un indígena cuya capa ostenta la cruz de Alcántara, seguramente se trata de un cacique donante. En la falda del cerro está el Inca Maita Cápac, el cual según algunos historiadores, es quien conquistó el Collasuyo" (GISBERT, 2010: 177). Esto posibilitaría pensar, cómo la imagen triangular de la Virgen encuentra conexiones con la forma de los cerros, la madre tierra y, en cierto punto, la cosmología andina. 
"padrinos" de esos objetos que se sacralizan en nombre de la advocación. Estos lexemas referidos al "padrinazgo" permiten entender cómo los promesantes no solo asumen ciertas tareas hacia el interior de los rituales sino la manera en la que también se identifican con roles familiares. Incluso, la misma denominación afectuosa de "Mamita" supone una relación de "hijos" con la divinidad y de hermandad entre los contactos interpersonales que se establecen entre los creyentes.

Por su parte, la Iglesia ha intentado disciplinar la práctica a través de diversas estrategias que se explorarán en este trabajo, un objetivo que se encuadra - también- en uno de los núcleos de indagaciones que piensan la regulación católica dentro de la pluralidad religiosa en Argentina (FRIGERIO, 2008, 2018).

Es necesario destacar que el municipio prohibió el uso de fuegos de artificios que se utilizaban en las procesiones que transitaban el espacio público y los medios de comunicación se encargaron de anclar la ordenanza municipal como una sanción para el culto de la Virgen de Urkupiña, cuando la disposición municipal dejó un vacío legal respecto a los eventos donde se prohíbe el uso de este elemento (NAVA LE FAVI, 2018, 2019). Esto permite pensar cómo desde diversos lugares de enunciación y poder se intenta controlar una práctica que tiene más cercanías con el carnaval bajtiniano que con las manifestaciones católicas canónicas.

\section{Entradas}

El trabajo retoma una mirada interdisciplinaria en el cruce de aportes que provienen de la semiótica, la comunicación cultura y estudios sobre la religiosidad de vertientes antropológicas, geográficas, históricas y sociológicas para comprender cómo la Iglesia Católica salteña ejerce el poder de controlar, disciplinar y legislar los espacios del culto de Urkupiña en la ciudad de Salta por ser -además- una devoción rizomática que se encuentra en un proceso constante de territorialización (DELEUZE y GUATTARI, 1972). Esta última categoría permite comprender los movimientos de expansión y de inscripción de ciertas prácticas sobre los territorios.

Para ello, se intenta explorar una serie de acontecimientos vinculados a la llegada de la Virgen a la ciudad de Salta en el año 2014, evento crucial para la historia de la devoción en el noroeste argentino, dado que era la primera vez que el bulto salía de su santuario en Quillaicollo, Bolivia, y visitaba un territorio extranjero. El recorrido 
que hace el bulto articula un relato espacial desde la visión eclesial lo que habla, de algún modo, sobre cómo la hegemonía piensa que se puede habitar y transitar la ciudad.

El trabajo explora cómo se significan los recorridos, las legislaciones espaciales y las fronteras en un acto de fijación y delimitación de un campo cerrado discursivo donde, de alguna manera, la Iglesia activa los campos de representación de esos espacios e impregna a la devoción con los mismos.

Este trabajo se centra en un evento particular: en el año 2013 la Iglesia Católica emite su primer comunicado en relación al culto denominado "La devoción a la Virgen de Urkupiña y Salta” donde invitaba a los devotos a formar parte de la llegada de la imagen cochabambina a la ciudad de Salta.

El comunicado firmado por la Arquidiócesis local designa, además, a la Iglesia del Pilar (ubicada en el macro-centro local) como la parroquia donde se oficiarían los rituales del culto. Este hecho no es menor considerando que los fieles llevaban sus imágenes a las parroquias ubicadas en sus barrios, lo cual implicaba múltiples procesiones por las calles de toda la ciudad. El Arzobispado propone esta Iglesia destacando que era la que tenía mayor antigüedad realizando los rituales. Sin embargo, su designación como parroquia de la Virgen de Urkupiña era temporal hasta que se construyera el Santuario en la zona sudeste de la ciudad de Salta.

Esta indagación, entonces, se pregunta sobre cómo existe una disputa entre diversas instituciones, agencias, imágenes de mundo y los espacios en las ritualidades de Urkupiña.

La obra foucaultiana en relación al poder brinda algunos posibles caminos para abordar el problema. Así, para el autor, esta categoría puede tener la función de prohibir, ocultar, excluir y lo hace mediante determinados discursos donde los sujetos son construidos como "desviados”, "locos”, “enfermos”, “delincuentes”. Allí, se puede leer los efectos del poder, los cuales oscilan entre repartir roles, posiciones y moldear individuos (FOUCAULT, 1975). Este aporte es útil para pensar cómo a los devotos de Urkupiña y sus prácticas son representadas, clasificadas y ordenadas de acuerdo a la visión del poder de la Iglesia.

Este abordaje utiliza la noción de representaciones sociales, es decir, mecanismos traductores, imágenes de mundo con carga ideológica (CEBRELLI y ARANCIBIA, 2005). También se considera el concepto de identificaciones, las cuales son pensadas como representaciones porque se sustentan en ideologías que se basan en prácticas y producciones comunicacionales capaces de construir el horizonte normativo 
donde se 'ordenan' los sentidos del mundo y de la vida (CEBRELLI y ARANCIBIA, 2005). Como lo plantea Stuart Hall (2003), la identificación es condicional pues sus condiciones de existencia están determinadas por los recursos materiales y simbólicos en los que se sostiene, en tanto son procesos que son construidos, situacionales, relacionales, estratégicos (BRUBAKER y COOPER, 2002). Las identidades, como representaciones, están inscriptas en territorios (CEBRELLI y ARANCIBIA, 2005).

El trabajo indagará una serie de acontecimientos vinculados a una historia de la Virgen considerando la mirada institucional de la Iglesia Católica Salteña, donde se puede observar cómo se articula un relato del espacio (DE CERTEAU, 1996) desde la hegemonía local inscripta en la Iglesia. La indagación retoma entrevistas y observaciones participantes que se efectuaron durante el mes de julio de 2014. El artículo explora, entonces, cómo se significan los recorridos, las legislaciones espaciales, las fronteras en un acto de fijación y delimitación de un campo cerrado discursivo donde, de alguna manera, la Iglesia activa los campos de representación de esos espacios e impregna a la devoción con los mismos. De esta manera, por ejemplo, al exponer el culto en un lugar destinado a los eventos turísticos y culturales, la institución le imprime a la devoción un anclaje que la sujeta al ámbito del espectáculo.

Las territorialidades que atraviesa el culto, entonces, funcionan como una sujeción de la imagen que le otorga una acentuación vinculada a las representaciones que posee la curia respecto a Urkupiña.

De este modo, el análisis se centrará en el poder que despliega el Arzobispado de Salta para controlar, vigilar, centralizar y regular el culto a la Virgen de Urkupiña. Para ello, se parte de la premisa que la Iglesia de Salta lleva a cabo un pensamiento abismal. Este concepto - propuesto por Boaventura de Sousa Santos (2010) - se asienta en la epistemología occidental dominante que refiere a una lógica que opera por la definición unilateral de las líneas radicales que dividen las experiencias, los actores y los saberes sociales entre los que son visibles, inteligibles o útiles (los que quedan de este lado de la línea) y los que son invisibles, ininteligibles. De algún modo, la Iglesia establece diferencias entre lo "salteño" y lo "boliviano" anclando el culto en esta segunda identidad y obliterando la gran cantidad de citadinos que son fervientes devotos del culto.

El trabajo se estructura en cuatro partes: en un primer momento, se trata de mostrar brevemente una contextualización histórica del culto. Luego, se intenta explorar cómo la Iglesia traza una cartografía abismal que va moldeando el culto como 
"migrante" y que se hace legible en el recorrido que atraviesa el bulto de la Virgen de Urkupiña de Cochabamba en su visita por la provincia y, en tercera instancia, cómo traza su recorrido en la ciudad de Salta durante el año 2014. Finalmente, se piensa cómo durante el recorrido de la Virgen en la ciudades le asigna una posición de "espectáculo" anclado en el "turismo", la cual se hace legible cuando la imagen visita el Centro de Convenciones, lugar cuyo relato espacial desde el Gobierno está destinado para este tipo de eventos ${ }^{7}$.

\section{La "Mamita" en Salta}

El origen mítico de la Virgen se localiza hacia fines de 1700 en Bolivia, en el sudoeste de Quillacollo, localidad de Cochabamba. Allí residía una humilde familia de campesinos. La hija menor constantemente subía al cerro hasta que un día de agosto se le apareció una señora a quien llamaba la "Mamita", apelativo que usan los devotos actualmente para denominar a la Virgen. La niña indicó a doctrineros del lugar y a su familia dónde estaba la Virgen exclamando en quechua "Jaqaypiña urqupiña, urqupiña", que en español significa "ya está en el cerro" (urqu=cerro, piña=ya está), de allí el nombre castellanizado de Urkupiña.

Actualmente, esta devoción trascendió la localidad de Quillaicollo y se expande hacia otros países, incluida la Argentina. En la zona del noroeste se ha insertado con ciertas particularidades: se puede sostener que es un culto migrante pues se trata de una Virgen "extranjera”, en tanto su origen histórico se encuentra en Bolivia. Este tipo de festividades posibilitan a los migrantes adscribirse a una tradición cultural donde se sienten partícipes en el marco de lazos de pertenencia identitaria (SERAFINO, 2010; GIORGIS, 2000). Los cultos migrantes tienen dos características que hablan de procesos diferenciales: por un lado, la identidad 'recuperada' al asociarse a una práctica religiosa del propio terruño, proceso que suele estar fomentado por la sociedad receptora y, por otra parte, una bolivianidad que se asume en el país receptor a partir de, por ejemplo, advocaciones, bailes, entre otros procesos culturales. Así, muchos de los migrantes participan por primera vez de los rituales que en su país no practicaban (GIORGIS, 2000). Algunos de los testimonios recogidos durante el trabajo de campo dan cuenta de esa segunda forma de adscripción identitaria: es el caso de Lidia, mujer de más de 70

\footnotetext{
${ }^{7}$ Si bien fueron más los lugares que visitó la imagen, por cuestiones de espacio en el artículo solo se explorarán estos dos. 
años nacida en Sucre, afirmaba que en su país no practicaba ni conocía el culto a Urkupiña, pero que en Salta lo realiza ininterrumpidamente hace más de 20 años ${ }^{8}$. En el hecho particular del pasaje de Bolivia a la región del noroeste argentino, el ritual se transformó: mientras que en el país vecino tiene una estructura que se sustenta en la exhibición de jerarquías eclesiásticas y políticas, en la ciudad capitalina depende más del devoto y con ello de los recursos con los cuales el creyente cuente para el festejo (NAVA LE FAVI, 2019). El paso de un culto oficial (Bolivia) a uno más comunitario (Salta) disemina y complejiza el ritual, es decir, se desterritorializa y se vuelve a reterriorializar en un proceso que pierde homogeneidad y se vuelve rizomático, por lo que adquiere una configuración que responde a un movimiento transversal, el cual no posee principio ni fin (DELEUZE y GUATTARI, 1972, p. 12).

Cabe destacar que en los periodos pre y poscolonial, lo que actualmente se conoce como Salta tenía múltiples contactos con la zona andina boliviana. Ya en el proceso de constitución de los estados nacionales la historia tradicional salteña comienza a escribirse por influencia de las elites locales, donde se funda como mito de origen una identidad ligada a la llegada de los españoles: ese "grado cero" de la historia local, es decir, el punto de partida, se tiñe como una interpretación hegemónica donde se prioriza el origen europeo y se niega como ancestros a los grupos originarios indígenas y a los contactos interculturales con el país vecino, Bolivia, que datan desde tiempos precolombinos. Este tipo de representación identitaria se difunde y generaliza por intelectuales locales, como Bernardo Frías o como el escritor Juan Carlos Dávalos, entre otros, quienes se encargan de reconstruir la historia y el pasado a través de una elaboración de la genealogía de las familias del poder donde se rescata el origen español de las mismas (ÁLVAREZ LEGUIZAMÓN, 2010).

La práctica de Urkupiña es rizomática porque, también, cumple con el principio de multiplicidad, el cual se lee en las vestimentas que se realizan para la Virgen: así, proliferan ropajes de todos los tamaños y colores. Esta multiplicidad del rizoma posibilita pensar cómo las agencias realizan diversas apropiaciones del culto.

\footnotetext{
${ }^{8}$ El testimonio fue recabado el 15 de julio de 2014. 


\section{El trazado de un culto migrante}

En el año 2013, se anunció la llegada de la Virgen de Urkupiña a Salta, la cual era "sacada” de su Santuario en Quillaicollo, Bolivia, por primera vez.

En las territorialidades marcadas por el camino de la Virgen en la provincia, se van mapeando los sistemas de pertenencia, los lugares que son de frontera como "las ciudades límite” o aquellas que tienen gran cantidad de bolivianos residentes. Esto posibilita "mirar" las representaciones que tiene la Iglesia del culto y sus devotos, es decir, existe allí un esfuerzo del pensamiento abismal por "localizar" desde el poder determinados espacios y actores que van dibujando un culto "migrante".

Podría sostenerse que los lugares prefijados por el Arzobispado de Salta para el recorrido de la Virgen en la ciudad marcan material y simbólicamente cómo se produce el posible ingreso de la devoción a la provincia según la Iglesia y, por el otro, cuáles serían los barrios/zonas de la ciudad donde se "localizan" la mayor cantidad de devotos de la "Mamita". El recorrido funciona, aquí, como una indicación performativa, un peregrinaje donde hay una mención de las etapas que debe seguirse y distancias en tiempos de camino (DE CERTEAU, 1996). Este recorrido fabrica un relato que describe desde las representaciones de la Iglesia cómo se fija el culto en el territorio local, es decir, cómo se conforma una cartografía que prescribe los lugares donde se inscribe la devoción.

Así, el 8 de julio de 2014, la imagen ingresa vía terrestre a la provincia por Salvador Mazza, una localidad del extremo norte de la Argentina perteneciente al Departamento General José de San Martín el cual se constituye en un espacio de paso internacional, una zona de frontera argentino-boliviana y, al mismo tiempo, periférica con respecto a los centros urbanos de Argentina en general y de la provincia de Salta, en particular (BENEDETTI y SALIZZI, 2014). El hecho que se haya oficiado una misa en esta localidad simboliza, también, la manera en la que se imagina ese "paso" de la devoción de Bolivia a Argentina, es decir, se re-activan las imágenes del mundo que piensan al culto como producto de esos intercambios de fronteras, justo en el límite entre un territorio y otro. Cabe destacar que, al establecerse un territorio, las ciudades "límite" operan como un sistema para establecer el alcance de ese "terruño" y el espacio diferencial con respecto al vecino, lo cual se convierte en generador de diferencias (BENEDETTI y SALIZZI, 2014). Así, el límite entre lo que es "boliviano” de lo que es 
"argentino"/“salteño” se ubica justo en esta localidad y va marcando, de alguna manera, cómo se imagina el culto en territorio argentino desde la óptica eclesial.

La imagen luego se traslada a la localidad de Tartagal, una ciudad fronteriza con Bolivia y perteneciente al Departamento General José de San Martín. Posteriormente lo hace vía aérea a las ciudades de San Ramón de la Nueva Orán, en el departamento de Orán. Ambos departamentos tienen la característica de ser los lugares de mayor concentración poblacional en el interior provincial: San Martín posee 156.910 habitantes y el Departamento de Orán 138.838 habitantes de acuerdo al Censo del año 2010. Antes de arribar a la ciudad de Salta su último lugar de parada es Perico que forma parte del Departamento El Carmen, en la provincia de Jujuy.

Cabe destacar que estos departamentos no son sólo importantes en cuanto a sus índices poblacionales. El Departamento de Orán tiene la peculiaridad de constituirse en una de las zonas de localización de cultivo de caña por sus características ambientales. Este desarrollo económico data desde los siglos XIX y XX y permitió que ciertas familias se conviertan en parte de la elite provincial, como el caso de los Uriburu, quienes tenían explotaciones de caña de azúcar y trapiches en la localidad. Además, junto a otras familias, tuvieron incidencia a nivel nacional: se incorporaron al Congreso de la Nación y a los gabinetes presidenciales y un integrante de la familia Uriburu llegó a ocupar la primera magistratura nacional (JUSTINIANO, 2008). Es decir, la actividad azucarera en este departamento fue una vía por la cual ciertos sectores tuvieron no sólo réditos económicos sino políticos. En el caso del Departamento de San Martín y, principalmente, de las localidades de Tartagal y Mosconi, éstas son zonas consideradas como una de las "cunas" del movimiento piquetero o de trabajadores desocupados, en tanto se configuran como espacios donde maduraron experiencias de lucha, organización política y económica, adquiriendo un rol preponderante en la conformación y orientación de numerosas agrupaciones piqueteras en todo el país. Este proceso se da en el marco de las políticas neoliberales impulsadas por el gobierno de Carlos Menem en la década del '90, las que provocaron un vertiginoso crecimiento de la pobreza y del desempleo en la Argentina. Este contexto socio-económico produjo la emergencia del movimiento piquetero, conformado esencialmente por trabajadores desocupados que estallaron en esta zona fronteriza del país (BENCLOWICZ, 2008).

Entonces, los lugares que atraviesa la imagen son de relevancia por las implicaciones en los procesos económicos, políticos y sociales que tuvieron dentro de la provincia, aunque periféricos en relación al centro capitalino. 
Al mismo tiempo, los lugares visitados no son únicamente los que poseen mayor densidad poblacional en el interior provincial sino que, además, tienen altos índices de población migrante con origen en el país surandino. Así, en Orán, de un total de 4.221 habitantes migrantes, 3.966 son bolivianos; en el Departamento General José de San Martín, de un total de 2.811 migrantes, 2.630 son del país vecino. En el caso del Departamento El Carmen, en Jujuy, se presenta el mismo fenómeno: hay 7.742 migrantes de los cuales 7.684 son de Bolivia. Es decir, son espacios donde existe una gran concentración de bolivianos y, de algún modo, son un índice identitario para pensar el culto como "migrante" desde la visión eclesial. Cabe reflexionar que los índices identitarios son aquellos elementos que funcionan como una marca reconocible para el destinatario de los mensajes y que permiten una localización geocultural (en este caso, poblacional y migrante) de los usuarios de dichos elementos (ARANCIBIA, 2015). En ese sentido, este tipo de operadores funcionan de una manera relacional generando focalizaciones diversas de acuerdo a las representaciones en las que se entroncan y a la funcionalidad que cumplen dentro de ellas. Así, los lugares elegidos como paradas en el camino de la Virgen poseen gran cantidad de migrantes bolivianos y hablan de un relato espacial que delinea cómo se piensa que el culto se espacializa en la provincia en tanto deja implícita la idea sobre qué cuerpos y qué identidades poseen los devotos de la "Mamita".

\section{La "Mamita” en los bordes de la ciudad}

En la ciudad de Salta, la Virgen ingresa el sábado 12 de julio del año 2014, primero por el barrio Autódromo, luego pasa por Barrio Solidaridad en la zona sudeste de la ciudad y de allí se traslada a la Catedral Basílica. A la noche, el bulto es llevado al Centro de Convenciones de la ciudad para simular una especie de "entrada folclórica" que se efectúa en Bolivia donde participaron los devotos con sus vírgenes, bailes de sikuris, morenadas y diabladas. El domingo 13 de julio, se traslada a la parroquia de San Joaquín y Santa Ana, emplazada en el barrio homónimo. Posteriormente, la llevan a la localidad de Vaqueros para, finalmente, quedarse en la Iglesia del Pilar donde se le ofician misas y la comitiva boliviana deja una réplica exacta del bulto que queda en la parroquia. 
El recorrido no sólo marca algunos de los bordes de la ciudad, sino que la única vez que ingresa la imagen al centro lo hace en la Catedral Basílica de Salta.

La ciudad de Salta tiene un total de 14.402 migrantes, de los cuales 10.756 son bolivianos. El mapa 1 (Figura 1) marca en color verde oscuro las zonas con residentes bolivianos mayores de 21 años, en amarillo oscuro los que tienen entre 17 a 21 años y en amarillo claro los que son niños y adolescentes entre 0-17 años. Los colores también responden a la mayor concentración poblacional de residentes migrantes (en verde oscuro mayor cantidad de habitantes, amarillo oscuro y claro menor proporción). Además, en diferentes colores se delimitan los lugares que fue atravesando el bulto de la Virgen por orden. 


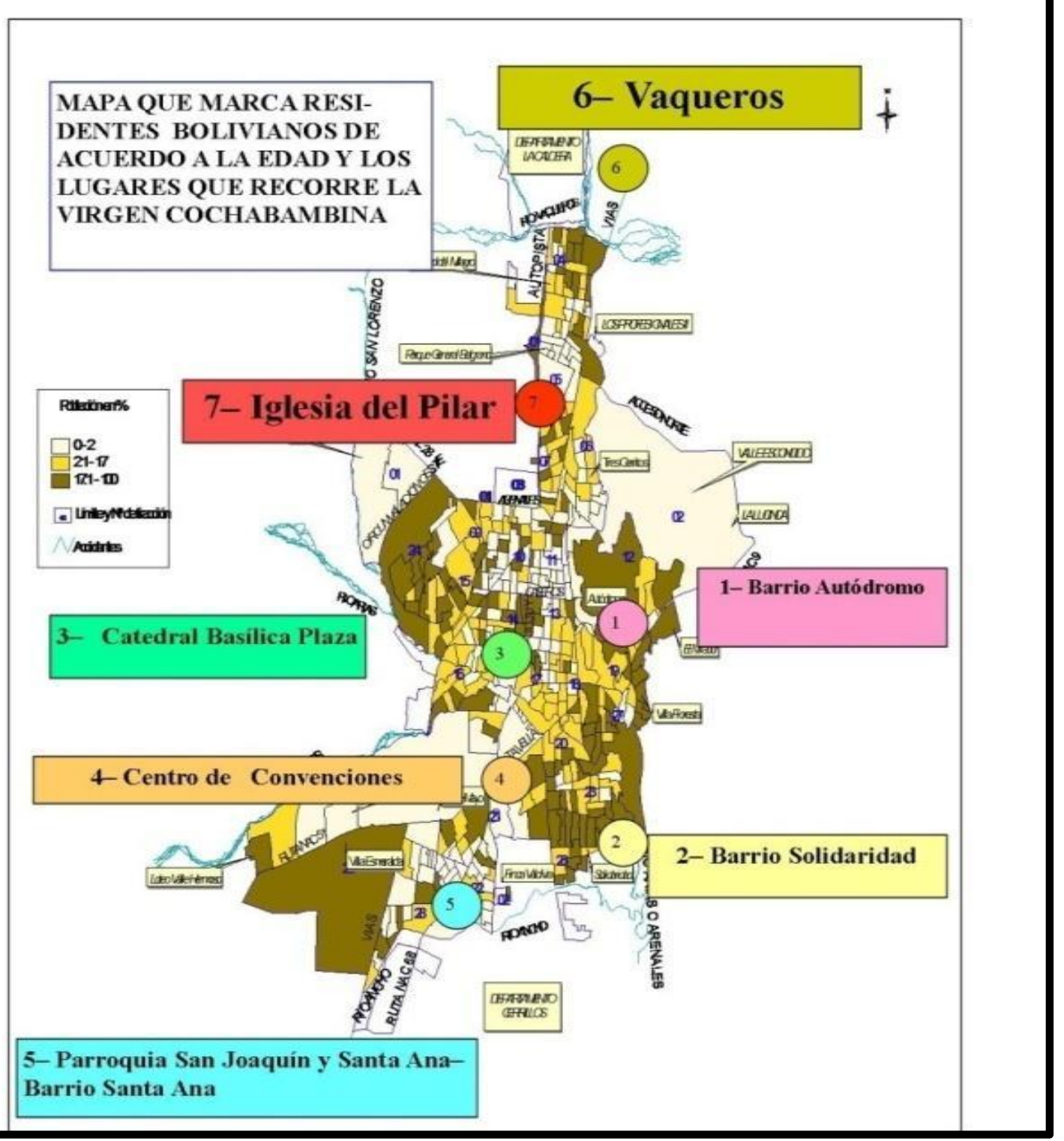

Figura 1: Mapa de la ciudad de Salta y los migrantes bolivianos.

Fuente: Elaboración propia realizada sobre la base del mapa de la Dirección de Estadística de la provincia de Salta.

Se puede observar, entonces, que el Barrio Solidaridad, Autódromo, la zona del macro centro donde se ubica la Iglesia del Pilar y Barrio Santa Ana, son los lugares que tienen mayor cantidad de residentes bolivianos mayores de 21 años. El mapa, entonces, marca una cartografía que escenifica un recorrido del culto en zonas que constituyen mayormente "bordes" de la ciudad con una gran concentración de migrantes del país vecino en el territorio local. 
Al igual que en la provincia, los barrios y lugares que atraviesa el recorrido del bulto focalizan desde qué lugar se ancla Urkupiña para las imágenes del mundo de la Iglesia salteña, es decir, una devoción que se imagina desde una cartografía abismal con un relato del espacio como preponderantemente "migrante" separando, de algún modo, lo que es "boliviano" de lo "salteño".

\section{Simulación y espectáculo}

Tal como se mostró en el mapa del recorrido de la Virgen en la ciudad, el centro de Convenciones se encuentra emplazado en la zona sur. El objetivo principal de este lugar es, según el Ministerio de Cultura, Turismo y Deportes de Salta, satisfacer la creciente demanda del segmento de turismo de reuniones que engloba la organización de congresos, ferias, exposiciones, eventos deportivos, viajes corporativos y de incentivo.

La Virgen atraviesa este lugar y se impregna, de algún modo, con las significaciones que circulan alrededor del culto y sirven para seguir moldeando el relato de la Iglesia. Desde acá es un culto que, además de ser migrante, puede mirarse desde la comercialización, es decir, desde un turismo que se exhibe y se puede vender. Desde el año 2015, posterior a este evento, han proliferado empresas de turismo que ofrecen paquetes para participar del culto en Cochabamba-Bolivia que incluyen viajes al lugar, paseos en el santuario, entre otros. De algún modo, la cartografía que traza la Iglesia funciona como índice de lo que se fue materializando a lo largo del tiempo.

En este lugar, además, se simuló la Entrada Folclórica que se realiza en Bolivia los días 14 agosto, un desfile de cerca de diez mil bailarines disfrazados y acompañados por músicos, evento inspirado en el Carnaval de Oruro. En Salta, numerosos devotos salteños y bolivianos se dieron cita para visitar la imagen día sábado 12 de julio, a partir de las 21 hs. Así, muchos promesantes se vistieron de caporales, sikuris, morenadas, diabladas y danzaron en un camino vallado con rejas blancas. En el centro del escenario se encontraba la imagen mariana custodiada por gente de la Iglesia y la comitiva boliviana. Cuando los devotos llegaban al bulto, hacían una reverencia y le daban paso al siguiente grupo que venía bailando atrás. A los costados de las vallas, había una multitud de espectadores tomando fotografías y ferias que iban desde comidas salteñas y bolivianas hasta ventas de alasitas y otros elementos rituales para el culto. 
Este desfile, que se extendió hasta después de la medianoche, escenificaba nuevamente las jerarquías impuestas desde el arzobispado: se disciplinaron los grupos de bailes, no se permitió tanta cercanía con la imagen y fue un momento de exhibición de los grupos de devotos bailarines. Surge allí, lo que Debord (1967) afirmaba acerca de la sociedad del espectáculo, en la cual existen los que contemplan y otros que son contemplados: "el espectáculo es así una actividad especializada que habla por todas las demás. Es la representación diplomática de la sociedad jerárquica ante sí misma, donde toda otra palabra queda excluida” (DEBORD, 1967, p. 25). Las personas devotas se limitaron a desfilar y reverenciar la imagen: el poder, aquí, actuó moldeando y disciplinando los cuerpos. La territorialidad donde se ubicó este desfile funcionó, a la vez, como un índice identitario de un relato que iba anclando la devoción también como parte de un espectáculo destinado al turismo.

\section{Cierres provisorios}

A lo largo del trabajo se intentó mostrar cómo la Iglesia salteña legisla el espacio del culto de la Virgen de Urkupiña intentando anclarla como un culto migrante y un espectáculo pero siempre en los bordes de la ciudad y no ocupando lugares centrales del imaginario urbano local.

En un primer acercamiento, se observó el caso de las localidades provinciales que visitó el bulto, como Orán o Tartagal, las cuales pueden ser pensadas como ciudades límites y fronterizas que impregnan con esa significación la imagen mariana y, también, las identidades de los devotos del culto.

En un segundo momento, se miró cómo el recorrido de la Virgen en la ciudad capitalina se hace en barrios ubicados en el borde de la ciudad. En el único momento que ingresa al centro es cuando visita la Catedral Basílica y lo hace por un periodo breve de tiempo. Con ese recorrido, se puede entender la necesidad de anclar el culto en el dominio eclesial al ingresar la imagen al templo más importante de la provincia, pero, se sigue manteniendo la concepción que es una advocación practicada únicamente por bolivianos cuando se ancla en barrios con mayor cantidad de migrantes de esta nacionalidad. Finalmente, cuando visita el centro de convenciones, el campo semántico que se activa es el de una devoción de "espectáculo” más que religiosa. 
De este modo, Urkupiña es delimitada no como un culto migrante asimilado por familias citadinas, sino, principalmente, como de bolivianos. No es religioso si no es en la Catedral y, fuera de ese espacio, se convierte en espectáculo. Los espacios, entonces, funcionan como marcadores identitarios de las imágenes de mundo que tiene la Iglesia de Salta respecto al culto.

Más allá de estos intentos de la Iglesia por disciplinar y legislar desde un pensamiento abismal una devoción andina, carnavalesca, se siguen sumando año tras año miles de devotos a la "Mamita".

\section{REFERENCIAS BIBLIOGRÁFICAS}

ÁLVAREZ LEGUIZAMÓN, Sonia. Introducción. En: S. ÁLVAREZ LEGUIZAMÓN (comp.), Poder y Salteñidad. Saberes, politicas y representaciones sociales. Salta: CEPHIA, Facultad de Humanidades, 2010.

ARANCIBIA, Víctor. Nación y puja distributiva audiovisual. Identidades, memorias y representaciones sociales en la producción cinematográfica y televisiva del NOA. Tesis (Doctorado en Comunicación) Universidad Nacional de La Plata, La Plata, 2015.

BAJTIN, Mijail (1998). La cultura popular en la Edad Media y en el Renacimiento: el contexto de Francois Rabelais. Barcelona: Alianza, 1998.

BENEDETTI, Alejandro y SALIZZI, Esteban. Fronteras en la construcción del territorio argentino. Cuadernos de Geografía: Revista Colombiana de Geografía, 23 (2), 2014, p. 121-138.

BENCLOWICZ, José. Los últimos grandes cortes de rutas puebladas de Tartagal- Mosconi. En: $V$ Jornadas de Sociología, UNLP, 2008.

BRUBAKER, Roger y COOPER, Frederick. Más allá de la identidad. Apuntes de investigación, 7 , 2002, p. 5-20.

CEBRELLI, Alejandra y ARANCIBIA, Víctor. Representaciones sociales: modos de mirar y de hacer. 1. ed. Salta: CEPIHA-CIUNSa, 2005.

CIRCOSTA, Carina. La fiesta-feria de alasitas en el la wak'a del parque avellaneda (c.a.b.a). Acerca de la presencia de los pueblos originarios y su incidencia en el arte y la cultura argentinos. Tesis (Maestría en Estudios Latinoamericanos), Universidad Nacional de La Plata, 2010.

DEBORD, Guy. La société du spectacle. Paris: Gallimard, 1967.

Comentarios sobre la sociedad del espectáculo. Barcelona: Anagrama, 1999.

DE CERTEAU, Michel. La invención de lo cotidiano. I. El arte de hacer. México: Universidad Iberoamericana, 1996.

DE SOUSA SANTOS, Boaventura. Decolonizar el saber, reinventar el poder. Uruguay: Trilce Extensión, Universidad de la República, 2010. 
DELEUZE, Gilles y GUATTARI, Félix. Mil Mesetas. Capitalismo y esquizofrenia. Valencia: PreTextos, 1972.

FOUCAULT, Michel. Los cuerpos dóciles. En: Vigilar y castigar: nacimiento de la prisión. Buenos Aires: Siglo XXI, 1975.

FRIGERIO, Alejandro. Diversidad no es lo mismo que pluralismo: cambios en el campo religioso argentino (1985-2000) y lucha de los evangélicos por sus derechos religiosos. Sociedade e Estado, 23(2), 2008, p. 227-260.

¿Por qué no podemos ver la diversidad religiosa?: Cuestionando el paradigma católico-céntrico en el estudio de la religión en Latinoamérica. Cultura y representaciones sociales, 12(24), 2018, p. 51-95.

GIORGIS, Marta. Urkupiña, la virgen migrante fiesta, trabajo y reciprocidad en el boliviano gran Córdoba. Cuadernos Facultad de Humanidades y Ciencias Sociales, Universidad Nacional de Jujuy, (13), 2000, p. 233-250.

GISBERT, Teresa. El cerro de Potosí y el Dios Pachamac. Chungará (Arica), 42, (1), 2010, p 169-180.

GUERRERO, Ana Lía; GALLUCCI, Soledad, MICHALIJOS, Paula y VISCIARELLI, Stella Marias. Países andinos: Aportes teóricos para un abordaje integrado de las perspectivas geográficas y turísticas. Revista Huellas (15), 2011, p 121-138.

GUARDIA CRESPO, Marcelo. Interacción humana y simbólica en rituales del Valle Alto de Cochabamba. Punto Cero, 23 (36), 2018, p. 49-63.

HALL, Stuart. Introducción: ¿quién necesita identidad? En: Stuart HALL y Paul DU GAY (comps.), Cuestiones de identidad cultural. Buenos Aires: Amorrortu, 2008.

Sin Garantías. Colombia-Ecuador: Envión Editores. Instituto de estudios sociales y culturales Pensar. Universidad Javeriana Instituto de Estudios Peruanos Universidad Andina Simón Bolívar, sede Ecuador, 2010.

JUSTINIANO, María Fernanda. Poder y riqueza en Salta a fines del siglo XIX: ¿Cuánto de vacas y cuánto de azúcar? Revista 7. Escuela de Historia. 7, (1), 2008, p. 1-24.

NAVA LE FAVI, Daniela. Bailar Morenada en la ciudad. Espacio público, identidades y colonialidad en las experiencias de devotas a la Virgen de Urkupiña en la ciudad de SaltaArgentina. Revista Andamios, 38 (15), 2018, p. 65-90.

La práctica de vestir a la Mamita: legitimidades, identidades, y arte popular en el caso de la Virgen de Urkupiña en la ciudad de Salta- Argentina. Cuadernos del Centro de Estudios en Diseño y Comunicación, 22, 2019, p. 185-195.

PODJAJCER, Adil y MENNELLI, Yanina. La mamita y la pachamama: las performances del carnaval y la fiesta de nuestra señora de la Candelaria en Puno y en Humahuaca. Cuadernos de Facultad de Humanidades y Ciencias Sociales, Universidad Nacional de Jujuy, 36, 2009, p.69-92.

SERAFINO, María Alicia. La celebración de una virgen migrante, construcciones identitarias entre bolivianos y santafesinos en un sector de Quintas al norte de la ciudad de Santa Fe Argentina. Sociedad Económica, 19, 2010, p.117-134. 